\title{
MARCELO H. DEL PILAR, EL MEJOR COMUNICADOR FILIPINO DE FINALES DEL SIGLO XIX
}

\section{MARCELO H. DEL PILAR, THE BEST PHILIPPINE COMMUNICATOR OF THE END THE XIX CENTURY}

\section{AUTOR}

\section{Enrique Ríos Vicente.}

Facultad de Ciencias de la Información de la Universidad Complutense y Presidente de la SEECl (España)

enrios@eucmax.sim.ucm.es

\section{RESUMEN}

Marcelo $\mathrm{H}$. del Pilar fue un buen periodista, un gran escritor y un mejor político que, desde las páginas del periódico La Solidaridad, y también por medio de artículos y folletos, promovió el liberalismo y luchó por la implantación de medidas sociales y políticas justas en Filipinas al mismo tiempo que criticaba abiertamente la situación privilegiada de los frailes en estas colonias.

\section{PALABRAS CLAVE}

Marcelo H. del Pilar - La Solidaridad - Fraile- Filipinas.

\section{ABSTRACT}

Marcelo $\mathrm{H}$. del Pilar was a good journalist, a great writer and a best political that, from the pages of the La Solidaridad, and also by the means of articles, promoted the liberalism and fight for the implantation of just social and political measures in 
Philippine at the same time that he criticized the privileged situation of friar and monk of this colonies.

\title{
KEY WORDS
}

Marcelo H. del Pilar - La Solidaridad - Monk - Phillipine.

\section{ÍNDICE}

1. Nace el comunicador (1882-1888)

2. Etapa periodística en Barcelona(1888-1890)

3. La etapa madrileña de Marcelo $\mathrm{H}$. Del Pilar

4. Bibliografía.

\begin{abstract}
"¿Es un mal para España la masonería filipina?
Pues cúlpese a los frailes. Éstos con sus imprudencias han ido empujando a los hijos de Filipinas a los brazos de la masonería"
\end{abstract}

Marcelo H. del Pilar

Marcelo Hilario del Pilar, "hizo famoso el seudónimo "Plaridel", en la revista La solidaridad y otras publicaciones, pertenecía al grupo de los reformistas filipinos que lucharon por las libertades de su país, contra la soberanía española" ${ }^{1}$.

Sin duda, esta información de La Veu de Catalunya, aparecida en 1920 con motivo de dar cuenta del traslado de los restos del gran líder filipino a Manila, inspirador del Katipunan, nos invita al acercamiento a uno de los personajes que gestaron la independencia de Filipinas tras la revolución del 30 de agosto de 1896 y los acontecimientos de 1898, aunque él no llegara a contemplar el estreno de la independencia. Precisamente le sorprendió la muerte en Barcelona (4 de julio de

\footnotetext{
${ }^{1}$ La Veu de Catalunya, 1920, 27 de octubre.
} 
1896) donde pretendía embarcar para ir a Filipinas y unirse al Movimiento La Propaganda.

El movimiento político conocido con el nombre de La Propaganda, tiene su inicio en 1882 y nace bajo el ansia de obtener reformas; pero al principio,

"su motivación no es la independencia nacional, sino el retorno a la anterior condición política de Filipinas como una provincia más de España. Por ello los mestizos filipinos y aun aquellos españoles nacidos en las islas consienten en unirse a los propagandistas filipinos en sus tareas, que no estiman sean lesivas a su lealtad $y$ amor patrios"2.

Las palabras anteriores se refieren en general a todos los líderes de la independencia filipina, pero sobre todo a Rizal que era totalmente contrario a conseguir la emancipación mediante métodos violentos. No son tan válidas para otros líderes, ya que en una segunda etapa de su vida se inclinaron por la necesidad de modos violentos ante la cerrazón de los políticos españoles que preferían pasar por alto la mayoría de edad de Filipinas, e incluso ignorar que aquellos territorios pretendían dejar de ser colonia y convertirse en una provincia más de España.

Aparte de Rizal, mártir por excelencia de la libertad filipina, hubo otros muchos líderes, pero algunos de ellos son desconocidos para el público español, incluso para el filipino. Hace más de un siglo, en 1891, Antonio Luna y Novicio, en su obra Impresiones, publicada en Madrid dijo de los españoles: "Lo único que saben es que en Filipinas hay mucho dinero y mucho fraile, como si dinero y fraile allí fueran inseparables" ${ }^{3}$.

\footnotetext{
${ }^{2}$ MOLINA, Antonio (1984): Historia de Filipinas, / y //, Madrid, pág. 272.

${ }^{3}$ LUNA Y NOVICIO, Antonio (1891): Mis impresiones, Madrid, pág. 5.
} 
Sin duda se refería al general desconocimiento de Filipinas por parte de los españoles. Cien años después, este año 98 nos exige y nos brinda al tiempo la oportunidad de investigar y dar a conocer algunas biografías claves en la preparación de la revolución, como la de Marcelo Hilario del Pilar. Por ello, vamos a tratar de acercarnos a uno de los comunicólogos políticos que más contribuyeron a la preparación de la revolución filipina, y en definitiva, a su independencia, que no llegó a ver hecha realidad.

¿Quién fue Marcelo Hilario del Pilar y Gatmaitan? Nació en Bulacán el 29 de agosto de 1850. Era hijo de Julián Hilario del Pilar y de Blasa Gatmaitán. El apellido materno lo relaciona con la nobleza tagala, ya que su madre era descendiente de uno de los reyezuelos indígenas de la época prehispana. Cursó sus primeros estudios bajo la tutela de un tío suyo, Alejo Marcelo. Después ingresa en el colegio de San José y en la Universidad de Santo Tomás de Manila para realizar estudios superiores. En la Universidad dominicana termina Derecho en el año 1880. Y en 1881 se gradúa. Casado con su prima Marciana, tuvo cuatro hijos. Durante algunos años ejerce la abogacía en un bufete con notable competencia, pero también la política, que iba a terminar ocupando toda su vida hasta su muerte ocurrida en Barcelona el 4 de julio de 1896, sorprendiéndole cuando iba a embarcar para Filipinas, a fin de enrolarse en la revolución en su país.

A Marcelo H. del Pilar se le suele catalogar como abogado, escritor y político, pero habría que decir que fue el político que aplicó todo su saber jurídico a la creación de su patria a través del periodismo y de la comunicación social. Una vez concluida su carrera de leyes, 1881, ejerce durante algunos años la profesión de abogado, pero su verdadera pasión era la política como ya apuntamos. No obstante, el desarrollo de la política en favor de las reformas en Filipinas, bajo una línea asimilista, como provincia española y no como colonia, lo iba a llevar a cabo a través de la comunicación social, charlas, conferencias, contactos con políticos, organización de manifestaciones, pero fundamentalmente a través de la edición de folletos en 
español y bilingües (español-tagalo) y a través del periodismo en el quincenario La solidaridad, que fundó Graciano López Jaena en Barcelona el 15 de febrero de 1889 con fondos del abogado filipino Pablo Rianzares.

\section{Nace el comunicador (188-1888).}

De sus primeros pasos en la enseñanza se sabe muy poco, a excepción de que fue confiado a un tío suyo, Alejo Marcelo, y, según Antonio Molina, a un "tal Flores" que le enseñaron las primeras letras. La segunda enseñanza la realizó en el Colegio de San José y en el de San Juan de Letrán de Manila y los estudios universitarios en la Universidad de Santo Tomás de Manila, donde se graduó de bachiller en Filosofía y posteriormente se licenció en Derecho ${ }^{4}$.

Toda la formación de Marcelo fue dentro del ámbito religioso: ámbito familiar, la segunda enseñanza en manos de los Institutos religiosos y monacales y la educación superior universitaria también en manos de los dominicos a través de la Universidad de Santo Tomás de Manila. De ahí que conociera perfectamente el mundo religioso no sólo por los contactos y la enseñanza, sino también a través de sus defectos y abusos, ya que conoció el Derecho Canónico a través de dos cursos en la Universidad. Todo ello le llevó a comprobar la preponderancia monacal en Filipinas y sus obstáculos a las reformas en el Archipiélago.

Existe un gran vacío y desconocimiento sobre las primeras actividades de Marcelo en su período de enseñanza, pero sin duda, sufrió un fuerte impacto en su personalidad el motín de Cavite de 1872, no sólo porque fueron juzgados sumarialmente 71 prisioneros ${ }^{5}$ sino por que trece fueron ajusticiados, y entre ellos tres sacerdotes, Gómez, Burgos y Zamora (acrónimo filipino GomBurZa) ${ }^{6}$. La sentencia se cumplió el

\footnotetext{
${ }^{4}$ VILLARROEL, Fidel (1997): Marcelo H. del Pilar: His Religious Conversions, Manila, págs 5-6.

${ }^{5}$ MOLINA, Antonio: Op. Cit. Pág 250-255.

${ }^{6}$ VILLARROEL, Fidel: Op. Cit. Pág. 7.
} 
17 de febrero de 1872. Además, entre los numerosos presuntos implicados, se encontraba el hermano mayor de Marcelo, el presbítero J acinto Hilario del Pilar, que fue deportado a las Islas Marianas. Sin duda, la algarada de Cavite con sus trágicas consecuencias iba a influir de modo decisivo en la trayectoria vital de Marcelo, que "tenía 21 años y estaba a las puertas de graduarse de bachiller en Filosofía, de modo que no podría olvidar la amarga experiencia de aquel castigo" ${ }^{7}$. Villarroel comenta que aunque la Iglesia no había dictado la sentencia contra los sacerdotes, la ejecución de GomBurZa había aumentado la brecha de animosidad entre el clero nativo y los frailes párrocos ${ }^{8}$.

Estos dramáticos sucesos encendieron la mecha del movimiento de Propaganda. Sin duda, estos acontecimientos reflejaron de alguna manera en Filipinas la revolución de septiembre de 1868, cuyas ideas libertarias ya habían prendido entre los estudiantes y quizá más en la mente de Marcelo por ser muy extravertido y sus estudios de leyes. Marcelo Hilario del Pilar estaba estudiando ya en la Universidad cuando aparecieron en las aulas hojas volantes contra miembros de la Facultad incluyendo a los frailes. Cabe preguntarse si el joven Marcelo estuvo implicado, pues fue un Martí filipino.

Es fácil colegirlo, ya que el mismo Marcelo cuenta en su folleto La Soberanía monacal la anécdota de:

"un joven estudiante de derecho que se presentó en una parroquia de cierto arrabal de Manila, para apadrinar el bautismo de una criatura nacida en otro arrabal: Vio que todos pagaban dos reales fuertes por el bautismo, pero a él le cobraron cuatro reales fuertes, $y$ ante la deficiencia del fundamento de semejante cobro mayor que los demás, no se negó a pagar, pero, con una sonrisa, observó que a

\footnotetext{
${ }^{7}$ VILLARROEL, Fidel: Op. Cit. Pág. 7.

${ }^{8}$ VILLARROEL, Fidel: Op. Cit.
} 
su juicio el arancel no autorizaba, para el bautismo otros derechos que el de una candela a voluntad del padrino".

La anécdota terminó con recriminaciones, insultos por parte del párroco, quien profirió "una expresión tan injuriosa como grosera", continúa Plaridel. Para no ser prolijos, por la amplitud de la cita, baste decir que el joven estudiante (¿Marcelo?) renunció a ser padrino en aquel bautizo. El párroco elevó un oficio al gobernador civil de Manila, donde se le acusaba al estudiante de "filibustero" y "antiespañol". El joven se entregó voluntariamente al juez y le metió en la cárcel. A no ser por la influencia de un convecino brigadier que convenció al gobernador de la inocencia del estudiante, éste lo hubiera pasado muy mal, pero aún así, estuvo recluido durante treinta días ${ }^{10}$.

A principios de los ochenta nació el Movimiento de Propaganda que desde el principio vio en los frailes el principal obstáculo para conseguir cambios radicales en la colonia a través de varias clases de reformas. Era frecuente en la década de los 80, dice Villarroel, que bachilleres, licenciados, filósofos, abogados, versados en español, mirasen por encima del hombro a gobernadorcillos y principales y desafiaran de igual a igual a los párrocos sobre materias de su especialización, ganando de ese modo prestigio entre el pueblo.

\section{Etapa periodística en Barcelona(1888-1890)}

Dado el carácter de Marcelo, es comprensible que fuera uno de estos graduados que se enfrentaban dialécticamente a frailes párrocos, a gobernadorcillos y principales desde el punto de vista dialéctico, máxime si tenemos en cuenta que termina sus estudios y graduación en Derecho en 1880-1881. Es el momento del retorno a Bulacán donde abre un bufete, pero todavía más importante es lo que nos descubra

\footnotetext{
${ }^{9}$ PLARIDEL, M. H. (1888): La soberanía monacal en Filipinas, pág. 9.

${ }^{10}$ VILLARROEL, Fidel: Op. Cit. Pág. 4
} 
Antonio Molina, que además de ejercer la profesión con notable competencia, Marcelo del Pilar hace política. En 1882 escribe mucho en el periódico Diariong Tagalog hasta que estima oportuno marchar a España para unirse al movimiento que va tomando auge con el nombre de La Propaganda, señala Antonio Molina en su obra $^{11}$.

Tengamos en cuenta que esa marcha a España iba a tener lugar a finales de 1888, lo que supone una primera actividad periodística importante, comunicación social realizada, además, en un medio tagalo. Marcelo $\mathrm{H}$. del Pilar se iba a manifestar como un gran escritor en tagalo, ya que escribió en esa lengua varios folletos, por lo que dice Villarroel, citando a Epifanio de los Santos, que no tuvo rival como periodista, polemista o publicista y que es como escritor tagalo cien veces superior a Rizal ${ }^{12}$.

Aunque en esos primeros años de su actividad, tanto política como periodística, trabajó sin desánimo por las reformas en Filipinas, más que como líder de la separación y de la independencia, en reivindicación de las reformas, en la preparación de la revolución que llegaría más tarde. En todos sus escritos mostraba, aparte de un buen estilo como escritor, una gran preparación cultural, de modo que más tarde el Gobernador de Filipinas (1893-1896), general Ramón Blanco diría de él que "Del Pilar era el más inteligente de todos, la voz verdadera de los separatistas, muy superior a Riza ${ }^{13}$. Aunque no sea correcto del todo el calificativo de separatista aplicado a Del Pilar a sus primeros años de activista de La Propaganda, sí se le podría aplicar más tarde cuando ya había fracasado todas las esperanzas de reformas auténticas, incluso las esperadas de parte del mundo liberal. Desde su vuelta a Bulacán tras los estudios de Derecho, Del Pilar se vio de modo constante comprometido en actividades que el gobierno provincial y los párrocos agustinos seguían con inquietud.

\footnotetext{
${ }^{11}$ MOLINA, Antonio: Op. Cit. Pág. 284.

${ }^{12}$ VILLARROEL, Fidel: Op. Cit. Pág. 4.

${ }^{13}$ MOLINA, Antonio: Op. Cit. Pág. 283.
} 
Marcelo H. del Pilar, así como el resto de los propagandistas y los intelectuales filipinos en general eran conscientes de que la iglesia a través de las Órdenes e Institutos religiosos habían invadido una buena parte de las competencias del Estado. Los mismos eclesiásticos se daban perfecta cuenta de ello y era favorecido desde las altas esferas como hizo el arzobispo de Manila, monseñor Pedro Payo, que en su defensa de los religiosos recordaba que los frailes y jesuitas eran los grandes auxiliares de la Administración; los máximos defensores de España en cada rincón del Archipiélago; que ellos eran el mejor instrumento para extinguir en las parroquias el menor intento de movimiento contra las autoridades; que gracias a ellos, la nación, con escasa fuerza militar, guardaban aquellos territorios en la mayor paz y sumisión. Estas realidades manifestadas por el arzobispo Payo y la constatación general de los hechos en ese sentido, hicieron que el movimiento de Propaganda convirtiera a los frailes en blanco de sus ataques. Uno de los primeros y más enérgicos críticos de los religiosos fue Marcelo $\mathrm{H}$. del Pilar.

Durante esos primeros años de Bulacán, Marcelo organizó a sus parientes y asociados a fin de oponerse a la intervención de los párrocos en los asuntos de gobierno municipal. Esa actitud llevó a Marcelo y sus compañeros a un enfrentamiento con Fray Felipe García. En el año 1887 se produjeron otros incidentes con motivo del decreto del Gobernador Civil de Manila (Benigno Quiroga, del Partido Liberal y decididamente anticlerical) que prohibía que se llevaran los cadáveres a la iglesia para los ritos del funeral. Pero la situación más alarmante fue la manifestación de un grupo de filipinos encabezados por sus principales y organizada por Doroteo Cortés y su inspirador Marcelo H. del Pilar.

Los manifestantes marcharon desde la ciudad de Santa Cruz hasta el palacio del Gobernador Civil de Manila, José Centeno, para presentarle la solicitud de expulsión del arzobispo de Manila, Pedro Payo, y de todos los frailes del Archipiélago. En las denuncias de la petición se acusaba al arzobispo de desobediencia a la autoridad 
civil, mientras los frailes eran señalados como hostiles a toda autoridad, ambiciosos, despóticos, acaudalados, peligrosos para el Gobierno. El manifiesto, dice Villarroel, estaba lleno de citas del Derecho Canónico y de las Leyes de Indias. Se supo más tarde que la confección del escrito y la organización era obra de muy pocos. El autor mencionado se pregunta si estuvo implicado Marcelo H. del Pilar. Posiblemente, ya que fue un eficaz propagandista; era un hombre de leyes y las mismas razones y argumentos se iban a ver después reflejados en varios de sus folletos, como $\mathrm{La}$ soberanía monacal filipina y La Frailocracia y en gran cantidad de artículos publicados en el periódico La Solidaridad. Antonio Molina dice que la manifestación había sido encabezada por Marcelo Hilario del Pilar, que se sabe la urdiera ${ }^{14}$.

Las actividades clandestinas de Marcelo y sus ataques contra los frailes llegaron a ser tan conocidos que las autoridades provinciales, tanto civiles como eclesiásticas le situaron en su punto de mira y le calificaban de filibustero y antiespañol. Por ello, en octubre de 1888, merced a unas denuncias contra él ante el Superior Provincial de los Agustinos, el Gobernador Civil de Bulacán ordenó abrir un expediente contra el abogado Don Marcelo del Pilar:

"en orden a establecer los hechos teniendo en cuenta algunos encuentros que él organizó con elementos que propagaban ideas contrarias a las representativas de la religión y contra los españoles" ${ }^{15}$.

Este expediente le costaría la deportación. Más tarde diría Marcelo H. del Pilar, con tonos erasmianos, en La Soberanía Monacal:

"No lo sabemos. Pero de los que van a la deportación, la mayoría son los que no besan la mano del cura, los que no pueden pagar sus

\footnotetext{
${ }^{14}$ MOLINA, Antonio: Op. Cit. Pág. 283.

${ }^{15}$ VILLARROEL, Fidel: Op. Cit. Pág. 11.
} 
deudas al fraile, los padres o maridos de hermosuras inconquistables, etc. "116.

\section{La etapa madrileña de Marcelo H. del Pilar.}

El Gobernador Civil de Bulacná firmó la deportación de Marcelo el día 30 de octubre de 1888, pero dos días antes, debido a sus amigos y compañeros de propaganda, el condenado se enteró de la decisión del gobernador y puso tierra de por medio en viaje hacia Hong-Kong con la intención de llegara a España. La nueva etapa de Marcelo no sólo iba a ser la más rica y variada, sino que supondría un cambio total de actitud respecto al modo de llevar las reformas a Filipinas, y en definitiva, a su independencia.

Antes de salir del país, dejó un comité de la Propaganda bajo la presidencia del abogado y amigo Doroteo Cortés. Bastante tiempo antes, conviene reseñarlo a título de documentación sobre su personalidad de la primera etapa, se reunió con los filipinos Pedro Serrano y Rafael Enríquez para componer una serie de escritos antimonacales en tagalo. Entre ellos un burlesco catecismo y un libro de plegarias, en palabras de Villarroel:

"una cruda burla de los religiosos y su religión... intentando introducir ridículas, grotescas y odiosas figuras de los frailes. El pequeño tratado habría de ser devastador para el candor de los católicos filipinos" ${ }^{117}$.

Durante su viaje a Barcelona redactó también otro folleto en tagalo: Sagot nang España sa hibik nang Filipinas (Respuesta de España al lamento de Filipinas) en el que tildaba a los frailes como fuente de todas las miserias, despiadado ladrón de la

\footnotetext{
${ }^{16}$ PLARIDEL, M. H.: La soberanía monacal en Filipinas, pág. 9.

${ }^{17}$ VILLARROEL, Fidel: Op. Cit. Pág. 13.
} 
viuda y del huérfano, perturbador de la paz de las familias y otros calificativos no menos graves. Los autores han señalado que este folleto es el más incendiario de los escritos de Marcelo H. del Pilar.

Sin embargo, el escrito más famoso de Marcelo H. del Pilar, que lo redactó también durante su viaje a España y que publicó en Barcelona en 1889, es, sin duda, La soberanía monacal en Filipinas, de estilo completamente diferente, sobrio, cargado de argumentos, aunque sin encarnios, acomodado al público español a quien quería conquistar, incluso a través de razonables y sinceros sentimientos patrióticos, ya que era partidario de la asimilación y de la unión de Filipinas a España. Aún no había recibido el desencanto definitivo. El lenguaje despiadado de los otros folletos, sobre todo La Respuesta de España al lamento de Filipinas, ha de ser considerado a la luz de un gran sentido de la propaganda, ya que el autor se lo dirigía directamente a los filipinos ante quienes quería desacreditar a los frailes mediante la exposición de denuncias, hechos y actitudes de todos conocidas. Los hechos que todos conocían y habían padecido eran los argumentos que Marcelo se ahorraba de exponer, no porque no los tuviera como demostró al escribir La soberanía monacal de Filipinas, La Frailocracia, o en los artículos de La Solidaridad que trataban esa temática.

Tanto Marcelo $\mathrm{H}$. del Pilar, como Rizal, y otros, masones o no, no atacaron a la Iglesia como institución, sino a los frailes, que a su juicio eran el mayor e insalvable obstáculo para desembocar en una asimilación y fraternal unión entre la colonia y la metrópoli. Por ello Del Pilar en el primer capítulo de La soberanía monacal en Filipinas subraya que:

"la impunidad de los atentados y la preponderancia de los elementos de la rebeldía, arranca la más triste persuasión de que ya España abdicó de su soberanía en favor del monaquismo filipino" ${ }^{18}$.

\footnotetext{
${ }^{18}$ PLARIDEL, M. H. (1888): La soberanía monacal, pág. 1.
} 
Al analizar el aspecto político del tema "los frailes en Filipinas" señala que:

"la ingerencia del fraile en el régimen de Filipinas es tan íntima, que sin dificultad alguna dispone del statu quo del país a despecho de la nación y de las instituciones. Encargado de casi todos los curatos, su misión parroquial reviste el doble carácter de órgano político y patrocinio popular"19.

Para mantener ese status quo, el monaquismo esgrime el argumento del peligro de la integridad nacional: "El peligro de la integridad nacional es el caballo de batalla de los frailes para imponer su preponderancia en Filipinas ${ }^{20}$. Cuando Marcelo analiza el aspecto económico dice que:

"el gobierno filipino carece de recursos para emprender obras públicas de primera necesidad; en cambio las Órdenes monacales levantan grandiosos y suntuoso conventos en Manila; y en cada parroquia de tres mil almas, erigen espacioso palacio para vivienda de un cura regular"21.

Respecto a los sentimientos patrióticos el autor filipino hace gala de deseos de fraternidad entre España y Filipinas:

"Por nuestra parte no deseamos más que se consoliden los sentimientos de fraternidad entre España y Filipinas, arrancando de raíz toda simiente de desunión, todo obstáculo a la fusión real y efectiva de sus respectivos intereses: que Filipinas respire la atmósfera de su madre patria, y una sola fe, un solo ideal, una sola esperanza vivifiquen las aspiraciones de ambos pueblos, llamados a

\footnotetext{
${ }^{19}$ PLARIDEL, M. H. (1888): La soberanía monacal, pág. 3.

${ }^{20}$ PLARIDEL, M. H. (1888): La soberanía monacal, pág. 9.

${ }^{21}$ PLARIDEL, M. H. (1888): La soberanía monacal, pág. 12.
} 
elaborar su bienestar común y sorprender al mundo con un porvenir de exhuberante ventura"22.

Los deseos finales de Marcelo eran compartidos por otros héroes y líderes importantes, como Rizal.

En no pocas ocasiones los propagandistas y todos aquellos que trataban de la asimilación para Filipinas, fueron tachados de antiespañolismo. Cuando vivía en Barcelona y era redactor de La Solidaridad, Del Pilar escribió un artículo titulado "Antiespañolismo":

"Nuestros adversarios nos llaman antiespañoles, porque no pensamos como ellos. Con igual derecho podríamos llamarlos antiespañoles, porque no piensan como nosotros. Demandamos para Filipinas las leyes de la Metrópoli; nuestros adversarios las rechazan para el Archipiélago. Demandamos para Filipinas la aplicación de los derechos que nuestro Código fundamental establece, como inherentes a la nacionalidad española; a nuestros adversarios les repugnan tales derechos... Tal es la diferencia que nos separa ¿En qué parte está el antiespañolismo? ¿En nosotros, que precisamente pedimos la plena españolización de Filipinas, o en los que pretenden alejar aquella región española de toda influencia jurídica, política y social de la Metrópoli?"123.

Apenas llega a Barcelona, finales de 1888, Marcelo establece rápidos contactos con filipinos residentes en la ciudad, publica su obra La soberanía monacal en Filipinas y se produce un hecho que le define como un hombre entregado a la comunicación social a través del periodismo desde las páginas de La Solidaridad. Graciano López

\footnotetext{
${ }^{22}$ PLARIDEL, M. H. (1888): La soberanía monacal, pág. 41.

${ }^{23}$ DEL PILAR, Marcelo H. (1892): "Antiespañolismo" en el diario La Solidaridad, Madrid, 15 de marzo.
} 
Jaena, propagandista, tuvo la idea de fundar ese periódico. Lo funda el día 15 de febrero de 1889, siendo el primer director, por nombramiento del abogado filipino Pablo Rianzares, que fue quien lo financió. Los objetivos fundamentales fueron luchar por la implantación de las reformas políticas y sociales en Filipinas y exponer los males que aquejaban al país con miras a encontrarles solución. También sirvió de portavoz de las aspiraciones de los filipinos residentes en España. Antonio Molina señala que pretendió defender los principios del liberalismo, y sobre todo, laborar por el respeto más escrupuloso de las bases jurídicas sobre las cuales los filipinos habían consentido colocarse bajo el dominio español: "son, a saber, las de igualdad y asimilación, a fin de formar con los otros componentes un cuerpo homogéneo, con los mismos derechos e idénticas obligaciones" 24 .

En realidad, La Solidaridad y todos los filipinos que escriben en el quincenario, hacen suyo el dilema que proponía su colaborador Rizal: o bien Filipinas permanece bajo el régimen español, pero con mayores derechos y libertades, o sean, en paridad con los otros componentes del territorio español, o se vería obligada a proclamarse independiente y soberana. Esta última alternativa, añade Molina, no es del deseo de nadie, porque sólo acarrearía mayores males a ambas partes.

A mediados de 1889, Graciano López J aena dimite como director de la Solidaridad y le sustituye Marcelo Hilario del Pilar, quien compra el periódico a su dueño, Pablo Rianzares. A principios de 1890 se traslada a Madrid y con él el diario que reanuda su publicación en la capital de España. Marcelo encuentra el escenario propicio para establecer todo tipo de contactos con políticos y personajes que podían actuar en pro de las reformas en Filipinas.

José Rizal y Marcelo Hilario del Pilar, encabezando un grupo de filipinos se entrevistan con Miguel Morayta, para que como Gran Oriente autorice la fundación de logias exclusivamente para filipinos. Muy pronto se fundó la logia "La Solidaridad"

${ }^{24}$ MOLINA, Antonio: Op. Cit. Pág. 285. 
en Madrid. A finales de 1890 también se crea una sociedad en Manila denominada La Propaganda, con el fin de sostener la Asociación Hispano-Filipina y al periódico La Solidaridad. A principios de 1891 fue establecido la primera logia de filipinos en Manila, debido a que a finales de 1890, Morayta había encargado al estudiante filipino Antonio Luna y Novicio la redacción de un proyecto de francmasonería filipina a semejanza de la española.

En 1892 Rizal había creado la Liga Filipina, pero en julio de ese mismo año sufrió un rudo golpe al ser publicado en la Gaceta de Manila el decreto del gobernador Eulogio Despujol desterrando a Rizal. Fue el momento para algunos filipinos de comenzar a pensar en alguna asociación más drástica. Ya en 1888 Romualdo Teodoro de Jesús, escultor y maestro de Rizal, había organizado una sociedad secreta con el fin de trabajar por la emancipación del Archipiélago, pero con métodos violentos. No tuvo éxito y fracasó por la extendida ideología entre los filipinos de conseguir las reformas de forma pacífica. Solamente en cierto momento Marcelo $\mathrm{H}$. del Pilar abogó por la creación de algo semejante.

El 7 de julio de 1892 la Gaceta de Manila publica el decreto del gobernador Eulogio Despujol sobre el destierro de Rizal. Debido a ello la Liga Filipina recibió un duro golpe. Por ello, ese mismo día un grupo de propagandistas se reunía en la casa de Deodato Arellano, cuñado de Marcelo $H$. del Pilar, y fundaban el Katipunan (Venerable Sociedad Suprema de los Hijos del Pueblo). Entre los que acuden a la cita secrete se encuentran Andrés Bonifacio, Valentín Díaz, Teodoro Plata y otros que se comprometen a que "la sociedad trabaje por librar al pueblo de sus sufrimientos, valiéndose esta vez de medios violentos" ${ }^{\prime 25}$. El autor mencionado cuenta cómo los fundadores firman con su propia sangre su inscripción como miembros, reviviendo de esa forma el antiguo rito filipino, que significaba fidelidad a lo pactado.

${ }^{25}$ MOLINA, Antonio: Op. Cit. Pág. 293. 
Aunque había sido fundado el Katipunan, Domingo Franco intenta dar nueva fuerza a la Liga Filipina de Rizal, incluso recibe ayuda del mismo Andrés Bonifacio, aún se confiaba en la solución de los problemas sin recurrir a los métodos violentos. No obstante, la sociedad no llega a prosperar, por lo que sus miembros se convencen de que ya no es posible la vía pacífica, y queda disuelta definitivamente en octubre de 1893.

La etapa de Madrid iba a representar para Marcelo $\mathrm{H}$. del Pilar de alguna manera la culminación de su vida de periodista trabajando y escribiendo en todo este tiempo de los temas más variados, aunque predominan los referentes a las reformas en Filipinas, sus problemas, el predominio de la "frailocracia" y otros muchos temas de política nacional e internacional del momento. Puede decirse que Marcelo Hilario del Pilar desarrolló la mayor parte del periodismo de su madurez en La Solidaridad que apareció en Madrid. Mientras en la etapa de Barcelona escribió tres artículos, uno de ellos sobre la "Asimilación de Filipinas", en su período de Madrid llegó a escribir 145. No obstante, sus ensayos más importantes los edita en Barcelona: La sobernía monacal en Filipinas, La frailocracia filipina e incluso Arancel de los derechos parroquiales en las islas Filipinas.

Aparte del seudónimo de Plaridel, que aparece en La soberanía monacal en Filipinas, utiliza otros seudónimos, como el L.O. Crame, firma de su primer artículo en La Solidaridad, "Carta de Borneo", fechado el 31 de enero de 1889. Refiriéndose a Manila dice:

"Parece entablado allí un pugilato moral entre el pueblo y sus antiguos fanatizadores. Publícanse libritos por frailes que atribuyen al masonismo, antiespañolismo o irreligión todo pensamiento, palabra u obra antitéticos al interés de los conventos; y en contra de tales acusaciones circulan otros en castellano y tagalo, en prosa y en verso, que acusan al fraile de contrariar las aspiraciones de España y 
el catolicismo, explotando a costa de una y de otro la ignorancia de los filipinos" 26 .

Otros seudónimos fueron "Carmelo" en "Pasce agnos meos", del 30 de junio de 1890; "Patos" en "Espíritu de Asociación" del 29 de febrero de 1892 y el mismo "Plaridel" (que ya había usado en La soberanía monacal) en "Sentido Común", del 15 de octubre de 1892. Releyendo sus crónicas y artículos de La Solidaridad, uno se convence de que fue uno de los grandes periodistas hispánicos de finales del siglo XIX.

Es sabido que Marcelo $\mathrm{H}$. del Pilar contribuyó de modo eficaz al establecimiento de la masonería en Filipinas, y es conocido que el mismo tuvo el grado 33. En uno de los artículos de La Solidaridad titulado la "Masonería Filipina" dice: ¿Es un mal para España la masonería filipina? Pues cúlpese a los frailes. Estos con sus imprudencias han ido empujando a los hijos de Filipinas a los brazos de la masonería.

"En otro tiempo eran los defensores del filipino; hoy que el filipino se siente explotado y tiranizado por los que le defendían, nada más natural que busque su apoyo en otra institución que le promete libertad, igualdad y fraternidad"27.

El líder filipino, el crítico más acerbo del estamento monacal filipino, no sólo iba a tener muchos enemigos y detractores por su osadía, sino también por su vinculación a la masonería. La Iglesia de aquel momento se quejaba amargamente de la deserción de personajes muy dotados como Rizal o Marcelo $\mathrm{H}$. del Pilar, por citar dos de los máximos representantes entre los líderes, sino también en esa vertiente de abrazo a la masonería. Muchos religiosos no perdonaron nunca la vinculación a la masonería, incluso algunos sólo volvieron a considerar a esos héroes cuando

\footnotetext{
${ }^{26}$ DEL PILAR, Marcelo H. (1889): "Carta de Borneo" en el diario La Solidaridad, Barcelona, 31 de enero.

${ }^{27}$ DEL PILAR, Marcelo H. (1893): "La masonería filipina" en el diario La Solidaridad, Madrid, 15 de septiembre.
} 
abjuraban de la masonería y se reconvertían, como fue el caso de Rizal. En cambio, otros líderes, como Del Pilar, cuya muerte y reconversión ha permanecido hasta hace poco en la penumbra, sigue siendo desconocido y jamás fue rehabilitado por parte de su atacada "frailocracia". Aquellos ataques produjeron en gran medida el entierro de su fama. No se lo perdonarían nunca. El estudio citado de Fidel Villarroel, religioso dominico actual, trata de acercarse a la figura de Marcelo $\mathrm{H}$. del Pilar y demuestra, no sólo las grandes razones del comportamiento de Marcelo $\mathrm{H}$. del Pilar, sino también su conversión a la masonería, así como su reconversión "in extremis" a la Iglesia, lo mismo que Rizal. Sin embargo pasaron muchos años hasta que, el profesor de la Universidad de Santo Tomás de Manila, Fr. Francisco Marín Solá encontrara el Diploma masónico de Marcelo $\mathrm{H}$. del PIlar y lo llevara a la Universidad de Manila (1929) ${ }^{28}$. También este autor estudia los últimos momentos de estancia de Marcelo H. del Pilar en Barcelona, la recepción de los sacramentos "in extremis" (Extremaunción y Viático), así como las actas de ingreso en el hospital, de defunción y enterramiento (pp. 27 a 55). Una de las deducciones más claras que se extraen de todas esas pruebas es que Marcelo $\mathrm{H}$. del Pilar fue un masón de conveniencia, a pesar de su amistad con Miguel Morayta, a quien consideraba como un "padre", y a pesar de su grado en la masonería y de su Diploma masónico. El mismo Marcelo lo afirma de alguna manera cuando echa la culpa a los frailes del triunfo de la masonería en Filipinas: "Pues cúlpese a los frailes. Estos con sus imprudencias han ido empujando a los hijos de Filipinas a los brazos de la masonería" 29.

Recuerda así mismo el mencionado autor, que Marcelo $\mathrm{H}$. del Pilar, presidió los oficios del funeral de la esposa de Miguel Morayta, de quien era gran amigo. Sin embargo no ocurrió lo mismo cuando murió Marcelo, casi olvidado, en manos de unos amigos. ¿Donde estaba Miguel Morayta? Y si estuvo en aquel momento o se enteró de su muerte ¿que es lo que pasó? Al final fue abandonado por unos y por otros y su memoria ha permanecido poco menos que en total oscuridad. Aunque

\footnotetext{
${ }^{28}$ VILLARROEL, Fidel (1997): Op. Cit. Pág. 55

29 DEL PILAR, Marcelo H. (1893): "La masonería filipina" en el diario La Solidaridad, Madrid, 15 de septiembre.
} 
Marceloa H. del Pilar tiene un mausoleo en Manila como uno de sus líderes, creemos que no se ha hecho justicia con él, pues tuvo una de las inteligencias más preclaras, y sin duda, fue el principal cerebro que señaló el camino a la revolución posterior a su muerte, ya que en sus contactos con Deodato Arellano, había sido el inspirador del Katipunan. Solicitamos la rehabilitación de "Plaridel".

\section{Bibliografía}

DEL PILAR, Marcelo H. (1892): "Antiespañolismo" en el Diario La Solidaridad. Madrid, 15 de marzo.

DEL PILAR, Marcelo H. (1889): "Carta de Borneo" en el Diario La Solidaridad. Barcelona, 31 de enero.

DEL PILAR, Marcelo H. (1893): "La masonería filipina" en el Diario La Solidaridad. Madrid, 15 de septiembre.

DIARIO La Veu de Catalunya (1920): Número del 27 de octubre.

LUNA Y NOVICIO, Antonio (1891): Mis impresiones. Madrid.

MOLINA, Antonio (1984): Historia de Filipinas, / y //. Madrid.

PLARIDEL, M. H. (1888): La soberanía monacal en Filipinas.

VILLARROEL, Fidel (1997): Marcelo H. del Pilar: His Religious Conversions. Manila. 